\title{
Pemodelan dan Rancang Bangun Autonomous Underwater Vehicle dengan Enam Propeller
}

\author{
Muhammad Afif, Natsir Habibullah, Eko Mursito Budi, \& Estiyanti Ekawati \\ Teknik Fisika \\ Institut Teknologi Bandung \\ muafif.afif@gmail.co
}

\begin{abstract}
Abstrak
Perancangan pengontrol biasanya dilakukan terlebih dahulu pada model atau simulasi. Terkadang terdapat parameterpamater model yang tidak diketahui dan sulit diidentifikasi sehingga menyebabkan model yang dibuat tidak sesuai dengan kenyataan. Akibatnya pengontrol yang dirancang pun tidak berfungsi dengan baik pada sistem nyata. Pada penelitian ini digunakan pendekatan eksperimen dan simulasi untuk merancang pengontrol pada Autonomus Underwater Vehicle (AUV). Digunakan sensor Inertial Measurement Unit (IMU) sebagai sistem navigasi untuk mengetahui pergerakan dan orientasi wahana.Parameter pemodelan diidentifikasi dengan menyocokkan respon simulasi dengan respon terukur dari sistem. Pengontrol AUV yang dirancang adalah pengontrol kecepatan, pengontrol posisi, dan pengontrol sudut orientasi AUV. Pengontrol yang digunakan menggunakan kontrol PID dengan metode penalaan Ziegler-Nichols. Pengontrol yang dirancang diterapkan pada sistem nyata dan simulasi. Hasil dari pengontrolan wahana dan simulasi ditampilkan dan dibahas. Perbandingan antara simulasi dan respon nyata menunjukkan keakuratan identifikasi parameter yang digunakan sebagai model sistem yang menunjukkan perlunya perbaikan.

Kata Kunci: pemodelan; autonomus underwater vehicle; identifikasi parameter; kontrol pid; ziegler-nichols; navigasi inersia.
\end{abstract}

\section{Pendahuluan}

Robot bawah air telah banyak dikembangkan dan digunakan dalam kehidupan manusia. Robot tersebut merupakan robot yang terhubung dan dikendalikan dari jarak jauh atau lebih dikenal dengan remotely operated vehicle (ROV). Penggunaan ROV saat ini masih terbatas karena tingginya harga operasional, kebutuhan operator, dan masalah keamanan. Teknologi robot bawah air berkembang menjadi robot yang otomatis secara penuh dan andal, umumnya disebut autonomous underwater vehicle (AUV). Sistem navigasi dan kontrol adalah dua tantangan utama dalam pengembangan AUV. Terdapat tiga metode navigasi utama yang digunakan untuk AUV, yaitu sistem navigasi inersial, navigasi akustik, dan teknik navigasi geofisika [1]. Informasi navigasi yang baik adalah kebutuhan utama pada pengoperasian AUV, sehingga dibutuhkan sensor dan pengumpulan data yang akurat.

Tantangan besar selain navigasi pada AUV, yaitu sistem kontrol. Dinamika sebuah wahana bawah air sangat tidak linear, penuh dengan parameter yang tidak pasti, konstanta waktu yang bervariasi, semakin tinggi orde dengan bertambahnya penggerak, gangguan gelombang, dan berubah titik pusat massa dan titik pusat apung karena pergerakan robot [3]. AUV juga harus memiliki kemampuan untuk mengolah data navigasi, kemudian membuat keputusan tentang aksi kontrol yang harus dilakukan guna mencapai tujuan. Pada makalah ini akan dibahas bagaimana membuat sebuah wahana bawah air yang dapat bergerak secara otomatis. Agar robot dapat bergerak secara otomatis dibutuhkan sistem kontrol yang dirancang dari eksperimen dan simulasi. Dalam penelitian ini juga ingin diketahui bagaimana performa sistem kontrol wahana yang dihasilkan melalui eksperimen dan simulasi.

\section{Permodelan}

Permodelan secara umum dibagi menjadi tiga bagian, yaitu permodelan motor, gerak translasi, dan gerak angular.

\section{Motor}

Masukan tegangan motor diatur oleh motor driver berdasarkan pulse width modulation (PWM), sehingga baling-baling akan berputar. Putaran baling-baling akan menghasilkan gaya dan momen putar mengikuti persamaan (1) dan (2).

$$
\begin{aligned}
& F_{m}=C_{m} \rho A r^{2} \Omega_{m}\left|\Omega_{m}\right| \\
& T=C_{T} A r^{3} \Omega_{m}\left|\Omega_{m}\right|
\end{aligned}
$$

\section{Gerak Translasi}

Gaya-gaya yang mempengaruhi motor akan menyebabkan percepatan translasi AUV, gaya-gaya tersebut adalah gaya motor, gaya gesek, gaya apung, dan berat AUV.

Gaya motor ditunjukkan pada persamaan (3). 


$$
\left[\begin{array}{c}
F_{x} \\
F_{y} \\
F_{z}
\end{array}\right]=R_{m}{ }^{T}\left[\begin{array}{c}
F_{m 1}+F_{m 2} \\
0 \\
F_{m 3}+F_{m 4}+F_{m 5}+F_{m 6}
\end{array}\right]
$$

Matriks rotasi, $R_{m}{ }^{T}$ digunakan untuk mengubah kerangka kerja gaya motor dari kerangka koordinat wahana menjadi koordinat tetap bumi. Matriks rotasi ditunjukkan pada persamaan (4).

$$
R_{m}{ }^{T}=\left[\begin{array}{ccc}
c \theta c \psi & s \phi s \theta c \psi-c \phi s \psi & c \phi s \theta c \psi-s \phi s \psi \\
c \theta s \psi & s \phi s \theta s \psi-c \phi c \psi & c \phi s \theta c \psi-s \phi c \psi \\
-s \theta & s \phi s \theta & c \phi c \theta
\end{array}\right]
$$

Koordinat tetap bumi dan kerangka koordinat wahana ditunjukkan pada gambar 1 .

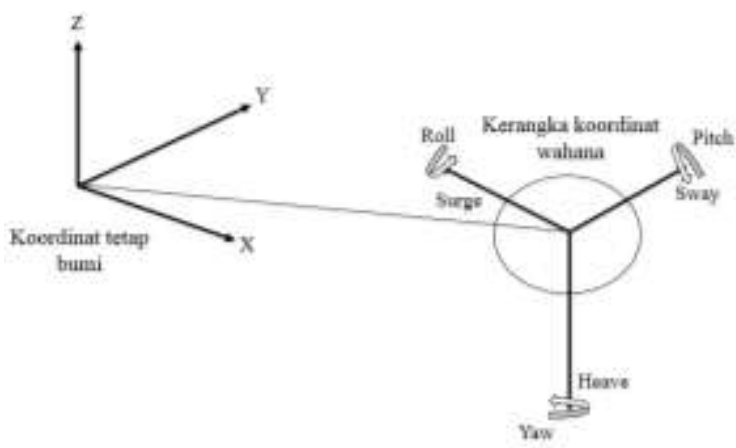

Gambar 14 koordinat tetap bumi dan kerangka koordinat wahana

Secara ringkas gaya total ditunjukkan pada persamaan (5).

$$
F_{n e t t}=\left[\begin{array}{c}
F_{x} \\
F_{y} \\
F_{z}
\end{array}\right]-\frac{1}{2}\left[\begin{array}{c}
C_{x} A_{c} \rho \dot{x}|\dot{x}| \\
C_{y} A_{c} \rho \dot{y}|\dot{y}| \\
C_{z} A_{c} \rho \dot{z}|\dot{z}|
\end{array}\right]-\left[\begin{array}{c}
0 \\
0 \\
\rho_{f} \forall g
\end{array}\right]+\left[\begin{array}{c}
0 \\
0 \\
m g
\end{array}\right]
$$

Sehingga percepatan yang dihasilkan ditunjukkan pada persamaan (6).

$$
\left[\begin{array}{c}
\ddot{x} \\
\ddot{y} \\
\ddot{z}
\end{array}\right]=\frac{F_{n e t t}}{m}
$$

\section{Gerak Rotasi}

Momen gaya total dihasilkan dari empat momen gaya yang mempengaruhi AUV, yaitu momen yang ditimbulkan oleh gaya apung dan gaya berat, momen akibat gaya dorong motor, momen putar motor, dan hambatan torsi. Secara ringkas momen total ditunjukkan pada persamaan (7).

$$
=\left[\begin{array}{c}
-d F_{a} \sin (\phi)+\left(F_{m 5}-F_{m 6}\right) c+\left(T_{1}+T_{2}\right)-\frac{1}{2} C_{\phi} A_{c} \rho \dot{\phi}|\dot{\phi}| \\
-d F_{a} \sin (\theta)+\left(F_{m 3}-F_{m 4}\right) b-\frac{1}{2} C_{\theta} A_{c} \rho \dot{\theta}|\dot{\theta}| \\
\left(-F_{m 1}+F_{m 2}\right) a+\left(T_{3}+T_{4}+T_{5}+T_{6}\right)-\frac{1}{2} C_{\psi} A_{c} \rho \dot{\psi}|\dot{\psi}|
\end{array}\right]
$$

Momen tersebut akan menghasilkan percepatan sudut AUV mengikuti persamaan (8).

$$
\left[\begin{array}{l}
I_{x x} \ddot{\phi} \\
I_{y y} \ddot{\theta} \\
I_{z z} \ddot{\psi}
\end{array}\right]=\left[\begin{array}{c}
\left(I_{y y}-I_{z z}\right) \dot{\theta} \dot{\psi} \\
\left(I_{z z}-I_{x x}\right) \dot{\phi} \dot{\psi} \\
\left(I_{x x}-I_{y y}\right) \dot{\theta} \dot{\phi}
\end{array}\right]+\tau_{n e t t}
$$

\section{Desain Wahana}

Elemen penting pada sistem robot bawah air terdiri dari empat komponen penting yaitu sumber daya berupa baterai Li-po dua sel, sensor unit pengukur inersia (IMU), aktuator berupa motor yang terhubung dengan baling-baling, serta pemroses berupa mikrokontroller arduino dan PC dengan perangkat lunak Matlab.

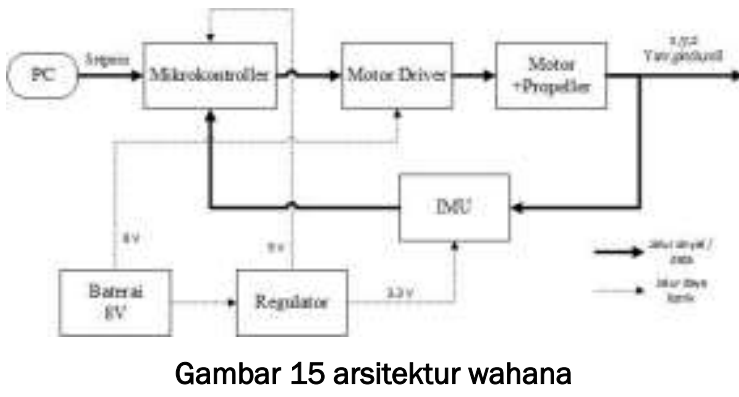

\section{Sistem Sensor}

Tidak seperti pada kendaraan darat yang memiliki teknologi GPS sebagai sistem navigasi, AUV yang beroperasi di bawah air tidak memiliki fasilitas tersebut [2]. Sensor yang digunakan adalah Inertial Measurement Unit (IMU). Inertial measurement unit (IMU) adalah alat elektronik yang mengukur percepatan, kecepatan, orientasi, dan gaya gravitasi dengan menggabungkan sensor akselerometer dan giroskop. Akselerometer adalah alat yang digunakan untuk mengukur percepatan translasi. Akselerometer akan selalu membaca percepatan gravitasi yang bekerja pada sumbunya. Dalam aplikasi navigasi untuk mendapatkan kecepatan dan posisi wahana, percepatan gravitasi tersebut harus dikompensasi terlebih dahulu. Percepatan gravitasi yang dialami oleh wahana dapat ditentukan dengan persamaan (9). 


$$
\left[\begin{array}{l}
g_{x} \\
g_{y} \\
g_{z}
\end{array}\right]=\left[\begin{array}{c}
\sin \theta \\
-\cos \theta \sin \phi \\
-\cos \theta \cos \phi
\end{array}\right]
$$

Percepatan pada tiap sumbu wahana diperoleh setelah mengompensasi gravitasi.

$$
\begin{aligned}
& a_{x}=a_{a c c x}-g_{x} \\
& a_{y}=a_{a c c y}-g_{y} \\
& a_{z}=a_{a c c z}-g_{z}
\end{aligned}
$$

Percepatan $a_{x}, a_{y}$, dan $a_{z}$ masih berupa unit g dan masih mengarah pada sumbu wahana. Untuk mendapatkan percepatan pada koordinat global matriks tersebut perlu ditransformasi menggunakan persamaan rotasi (4). Kecepatan translasi dan posisi wahana dapat ditentukan dari nilai percepatan dengan melakukan integral.

Giroskop merupakan sensor yang membaca kecepatan sudut. Untuk mendapatkan orientasi kemiringan wahana digunakan quaternion. Quaternion adalah bilangan kompleks empat dimensi yang digunakan untuk merepresentasikan orientasi sebuah benda tegar pada ruang tiga dimensi. Quarternion berpropagasi seiring dengan berubahnya orientasi sensor, laju perubahan quartenion ditunjukkan oleh persamaan (13) [5].

$$
\dot{q}=\left[\begin{array}{c}
\dot{q}_{1} \\
\dot{q}_{2} \\
\dot{q}_{3} \\
\dot{q}_{4}
\end{array}\right]=0.5\left[\begin{array}{cccc}
q_{1} & -q_{2} & -q_{3} & -q_{4} \\
q_{2} & q_{1} & -q_{4} & q_{3} \\
q_{3} & q_{4} & q_{1} & -q_{2} \\
q_{4} & -q_{3} & q_{2} & q_{1}
\end{array}\right]\left[\begin{array}{c}
0 \\
\omega_{x} \\
\omega_{y} \\
\omega_{z}
\end{array}\right]
$$

Nilai quaternion tiap waktu dapat dijadikan orientasi wahana dalam vektor arah gravitasi dengan persamaan (14)-(16).

$$
\begin{aligned}
& g_{x}=2\left(q_{2} q_{4}-q_{1} q_{3}\right) \\
& g_{y}=2\left(q_{1} q_{2}+q_{3} q_{4}\right) \\
& g_{z}=q_{1}{ }^{2}-q_{2}{ }^{2}-q_{3}{ }^{2}+q_{4}{ }^{2}
\end{aligned}
$$

Vektor arah gravitasi tersrbut dapat diubah menjadi sudut orientasi wahana dalam yaw, pitch, roll dengan persamaan (17)-(19) [4].

$$
\begin{aligned}
& \phi(\text { roll })=\arctan \left(\frac{g_{y}}{\sqrt{g_{x}^{2}+g_{z}^{2}}}\right) \\
& \theta(\text { pitch })=\arctan \left(\frac{g_{x}}{\sqrt{g_{y}^{2}+g_{z}^{2}}}\right)
\end{aligned}
$$

$$
\psi(\text { yaw })=\arctan 2\left(\frac{2\left(q_{2} q_{3}-q_{1} q_{4}\right)}{2\left(q_{1}{ }^{2}\right)+2\left(q_{2}{ }^{2}\right)-1}\right)
$$

\section{Sistem Propulsi}

Sistem penggerak wahana yang digunakan adalah baling-baling yang dihubungkan dengan motor DC. Peletakan motor dan baling-baling didasarkan pada tujuan desain AUV untuk mampu bergerak dengan enam derajat kebebasan yaitu surge, sway, heave, roll, pitch, and yaw. Hasil desain yang akhirnya dibuat menggunakan enam motor dengan konfigurasi pada gambar 2

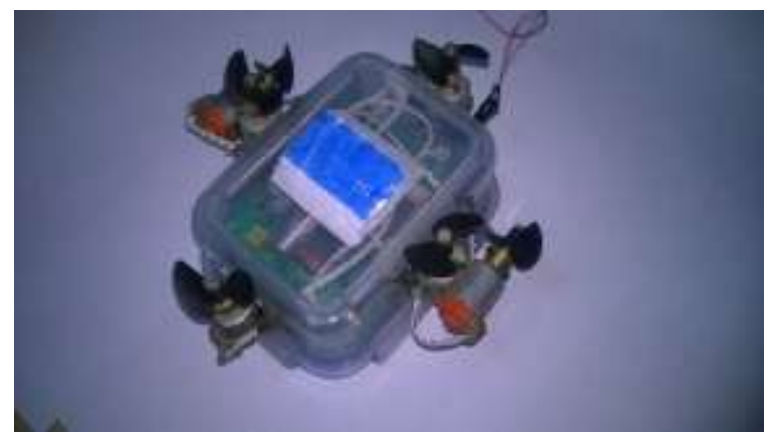

\begin{tabular}{|c|c|c|}
\hline No & Parameter (simbol) & Nilai (satuan) \\
\hline 1 & Gravitasi (g) & $9.81(\mathrm{~m} / \mathrm{s} 2)$ \\
\hline 2 & Massa jenis air (rho) & $1000(\mathrm{~kg} / \mathrm{m} 3)$ \\
\hline 3 & $\begin{array}{l}\text { PWM maksimum } \\
\text { (PWMmaks) }\end{array}$ & $255(-)$ \\
\hline 4 & $\begin{array}{l}\text { Konstanta EMF } \\
\text { (Kemf) }\end{array}$ & $\begin{array}{l}0.0121 \\
\text { (Volt.s/rad) }\end{array}$ \\
\hline 5 & $\begin{array}{l}\text { Koefisien torsi motor } \\
\text { (Ktm) }\end{array}$ & $0.0046(\mathrm{Nm} / \mathrm{A})$ \\
\hline 6 & Inersia motor (Jm) & $\begin{array}{l}4.10-7 \\
\text { (Nm.s2/rad) }\end{array}$ \\
\hline
\end{tabular}

Gambar 16 penempatan propulsi motor

\section{Identifikasi Parameter}

Identifikasi dilakukan dengan tiga cara, yaitu menggunakan nilai-nilai yang sudah umum digunakan atau sudah ada, melakukan pengukuran, dan menentukan nilai berdasarkan respon yang dihasilkan oleh simulasi.

Parameter yang nilainya sudah umum digunakan atau sudah ada ditunjukkan pada tabel 4-1.

Tabel 1 Nilai identifikasi parameter umum atau sudah ada 
Parameter yang nilainya ditentukan berdasarkan hasil pengukuran ditunjukkan pada tabel 4-2.

Tabel 2 Nilai identifikasi parameter hasil pengukuran

\begin{tabular}{|c|c|c|}
\hline No & Parameter (simbol) & Nilai (satuan) \\
\hline 1 & $\begin{array}{l}\text { Tegangan maksimum } \\
\text { (Vmaks) }\end{array}$ & 8 (Volt) \\
\hline 2 & $\begin{array}{l}\text { Hambatan dalam } \\
(\mathrm{Rm})\end{array}$ & 25 (Ohm) \\
\hline 3 & Luas permukaan (Ac) & $0.0504(\mathrm{~m} 2)$ \\
\hline 4 & Massa (m) & $0.67(\mathrm{~kg})$ \\
\hline 5 & Volume (V) & $680(\mathrm{~mL})$ \\
\hline 6 & $\begin{array}{l}\text { Inersia pada sumbu } x \\
\text { (Ixx) }\end{array}$ & $\begin{array}{l}0.00076 \\
\text { (kg.m2) }\end{array}$ \\
\hline 7 & $\begin{array}{l}\text { Inersia pada sumbu y } \\
\text { (lyy) }\end{array}$ & $\begin{array}{l}0.00105 \\
\text { (kg.m2) }\end{array}$ \\
\hline 8 & $\begin{array}{l}\text { Inersia pada sumbu z } \\
\text { (Izz) }\end{array}$ & $\begin{array}{l}0.00136 \\
\text { (kg.m2) }\end{array}$ \\
\hline 9 & Jarak (d) & $2(\mathrm{~cm})$ \\
\hline 10 & Jarak (c) & $6(\mathrm{~cm})$ \\
\hline 11 & Jarak (b) & $7(\mathrm{~cm})$ \\
\hline 12 & Jarak (a) & $7(\mathrm{~cm})$ \\
\hline
\end{tabular}

Parameter yang nilainya ditentukan berdasarkan respon oleh simulasi ditunjukkan pada tabel 4-3.

Tabel 3 Nilai identifikasi parameter hasil respon simulasi

\begin{tabular}{|l|l|l|}
\hline No & Parameter (simbol) & Nilai (satuan) \\
\hline 1 & $\begin{array}{l}\text { Koefisien gaya motor } \\
(\mathrm{Cm})\end{array}$ & $0.005(-)$ \\
\hline 2 & $\begin{array}{l}\text { Koefisien gaya gesek } \\
(\mathrm{Cx})\end{array}$ & $0.35(-)$ \\
\hline 3 & $\begin{array}{l}\text { Koefisien gaya gesek } \\
(\text { Cy })\end{array}$ & $0.35(-)$ \\
\hline 4 & $\begin{array}{l}\text { Koefisien gaya gesek } \\
\text { (Cz) }\end{array}$ & $0.55(-)$ \\
\hline 5 & $\begin{array}{l}\text { Koefisien gesek putar } \\
\text { (Cyaw) }\end{array}$ & $0.00003(\mathrm{~m})$ \\
\hline
\end{tabular}

\begin{tabular}{|l|l|l|}
6 & $\begin{array}{l}\text { Koefisien gesek putar } \\
\text { (Croll) }\end{array}$ & $0.00007(\mathrm{~m})$ \\
\hline 7 & $\begin{array}{l}\text { Koefisien gesek putar } \\
\text { (Cpitch) }\end{array}$ & $0.0001(\mathrm{~m})$ \\
\hline
\end{tabular}

Perbandingan hasil uji coba dengan simulasi menggunakan parameter pada tabel 4-3 dapat dilihat pada gambar 3 dan 4 .

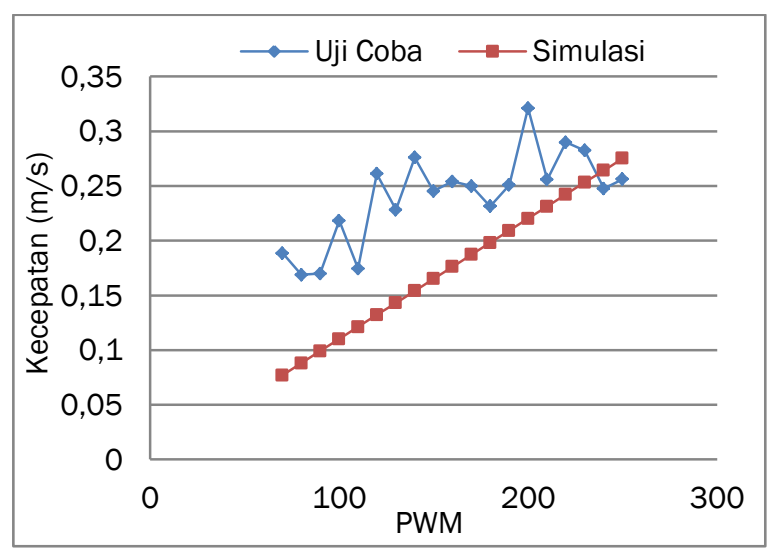

Gambar 17 kecepatan AUV hasil uji coba dan simulasi

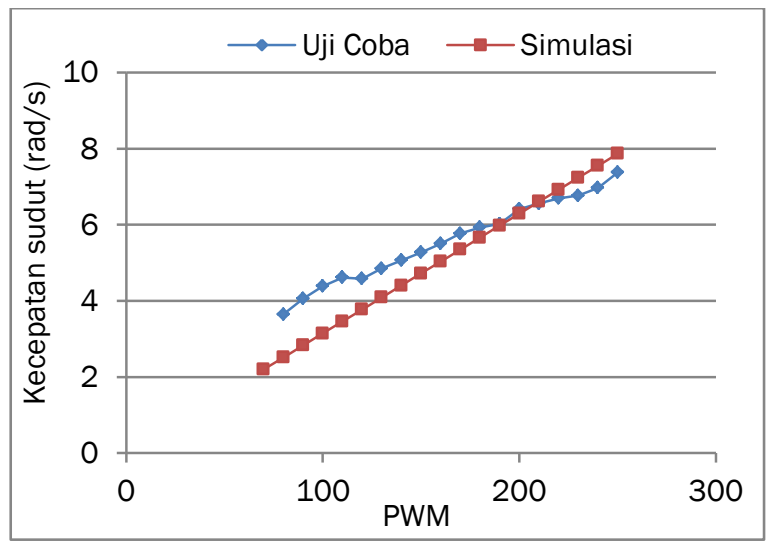

Gambar 18 kecepatan sudut AUV hasil uji coba dan simulasi

Nilai koefisien gaya motor dan gaya gesek ditentukan sehingga pada pemberian input maksimum 250 PWM kecepatan AUV pada simulasi mendekati kecepatan AUV hasil uji coba ditunjukkan pada gambar 3. Pengubahan nilai kedua konstanta ini akan mengakibatkan pergeseran signifikan terhadap kecepatan AUV pada simulasi. Nilai koefisien gesek putar ditentukan sehingga pada pemberian input yang membuat AUV bergerak secara pivot kecepatansudut yang dihasilkan simulasi mendekati hasil uji coba ditunjukkan pada gambar 4 .

\section{Perancangan dan Pengujian Pengontrol}

Diinginkan tiga pengontrolan yang dapat dilakukan oleh AUV yaitu pengontrol kecepatan, pengontrol 
posisi, dan pengontrol sudut geleng (yaw).Pengontrol yang dirancang adalah pengontrol PID dan metode yang digunakan dalam perancangan pengontrol yaitu metode Ziegler-Nichols [6].

Kecepatan memiliki respon input step yang berbentuk-S, maka parameter pengontrol untuk kecepatan menggunakan metode pertama ZieglerNichols. Input step diberikan pada wahana dan diamati respon kecepatan yang dialami wahana, dari respon tersebut ditentukan nilai $T$ dan $L$ untuk nilai input step 70-250 pwm. Dengan mengambil rata-rata dari nilai $T$ dan $L$ yang diperoleh dari percobaan input step, didapatkan parameter pengontrol PI untuk kecepatan yaitu Kp 4900 dan Ti 1.25. Parameter pengontrol tersebut diaplikasikan pada model simulasi dan wahana yang telah dibuat dan dilihat hasilnya. Hasil dari pengujian pada wahana dan simulasi dapat dilihat pada gambar 6 dan 7. Dari hasil respon yang diperoleh dapat dilihat bahwa kecepatan berhasil dikontrol baik dari sistem nyata maupun simulasi.

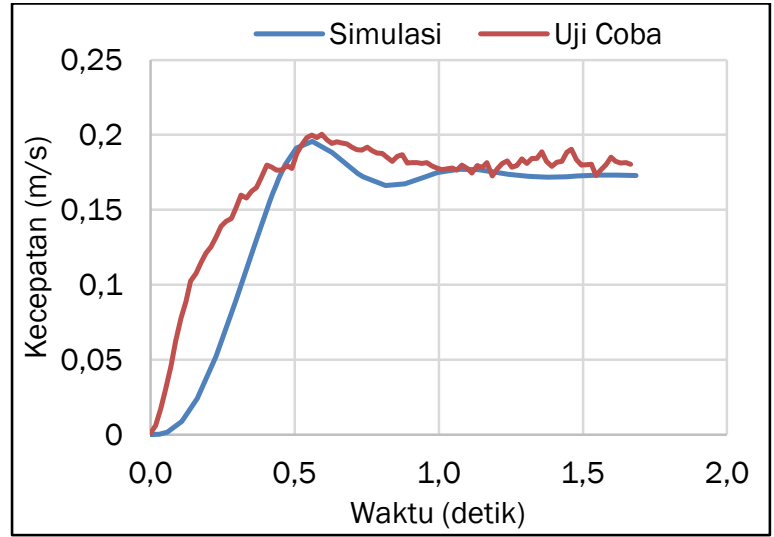

Gambar 19 kecepatan AUV dengan pengontrol PI dengan setpoint 0.17

Respon input step untuk Posisi dan sudut yaw tidak memiliki bentuk-S seperti pada respon input step kecepatan, sehingga metode pertama ziegler-nichols tidak dapat digunakan pada perancangan pengontrol posisi dan sudut yaw. Metode kedua Ziegler-Nichols dapat digunakan untuk merancang pengontrol posisi dan sudut yaw, namun terdapat kesulitan dalam menentukan gain kritikal Kcrpada metode kedua tersebut. Hal tersebut dikarenakan terbatasnya range input yang dapat diberikan kepada wahana yaitu hanya 0-255 pwm. Nilai gain kritikal tidak dapat ditemukan karena nilai gain yang berpengaruh terhadap input pwm juga menjadi terbatas.Perancangan pengontrol untuk posisi dan sudut yaw akhirnya dilakukan secara coba coba dengan memperkirakan nilai error dan juga mempertimbangkan nilai maksimum pwm.

Nilai parameter pengontrol untuk kontrol posisi yaitu Kp 2500dan Td 0.5. Hasil pengujian kontrol posisi dengan setpoint 0.4 meter untuk wahana dan simulasi dapat dilihat pada gambar7. Nilai parameter untuk pengontrol sudut yaw yaitu Kp 1000dan Td0.1. Hasil pengujian pengontrol dapat dilihat pada gambar 8. Pengontrol posisi berhasil pada sistem nyata dan simulasi meskipun masih belum efektif. Pengontrol sudut hanya berhasil pada sistem nyata, sedangkan pada simulasi sistem berosilasi jauh dari setpoint.

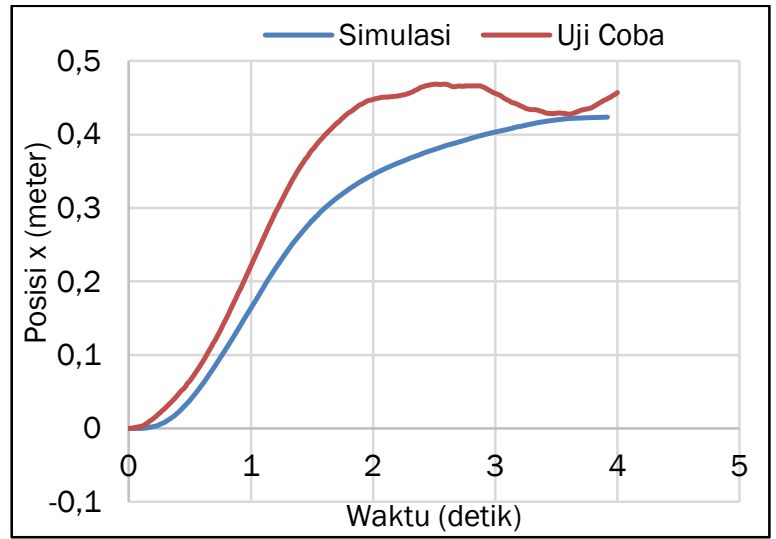

Gambar 20 posisi sumbu-x AUV dengan pengontrol PID

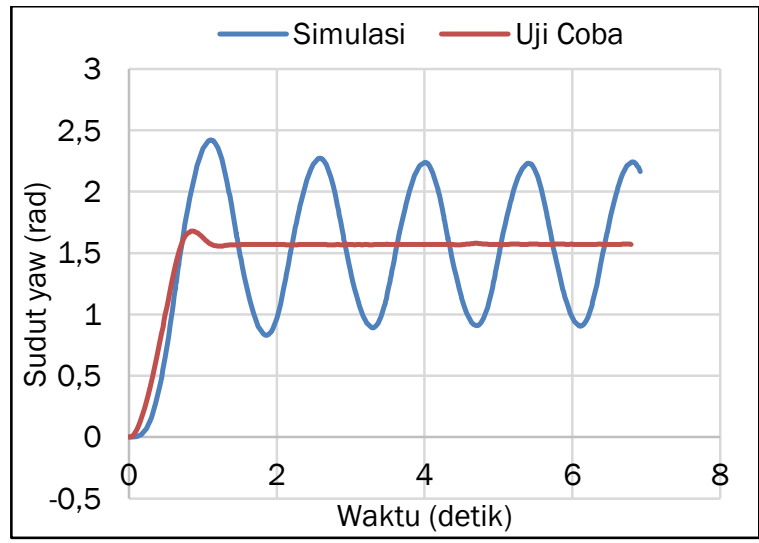

Gambar 21 sudut yaw AUV dengan pengontrol PI setpoint $1.57 \mathrm{rad} / 90$ derajat

Pengujian yang dilakukan pada wahana dan simulasi memberikan hasil pengontrolan yang cukup mirip pada pengontrolan kecepatan dan pengontrolan posisi yang merupakan gerak translasi. Sedangkan pada pengontrolan sudut atau gerak rotasi, hasil pengontrolan wahana memberikan hasil yang berbeda dibandingkan dengan pengontrolan pada simulasi. Kesamaan dan perbedaan antara pengujian wahana dan simulasi mengindikasikan bahwa model yang digunakan untuk simulasi cukup menyerupai sistem nyata untuk gerak translasi, tetapi masih kurang akurat untuk gerak rotasi.

Pada gambar 5 dapat dilihat bahwa respon kecepatan sudut dari input step yang dicapai wahana dan simulasi sudah mendekati, tetapi hal tersebut belum cukup untuk memastikan parameter pemodelan yang 
didapat sudah mendekati sistem nyata. Pemodelan gaya hambat untuk gerak rotasi masih perlu diperbaiki dan juga memerhatikan kemiripan waktu konstan dari respon input step karena model yang sekarang memiliki perbedaan dalam waktu konstan. Waktu konstan hasil simulasi lebih cepat daripada sistem nyata, hal ini menyebabkan pengontrolan sudut pada simulasi lebih berosilasi daripada ujicoba.

\section{Kesimpulan}

Pemodelan dilakukan dengan memperhitungkan gaya-gaya yang bekerja pada sistem serta interaksinya dengan sistem dan lingkungan di sekitar sistem. Parameter yang tidak diketahui dari sistem ditentukan dengan cara menyesuaikan respon simulasi dan respon terukur dari wahana. Parameter pemodelan yang diperoleh ditampilkan pada tabel 1 tabel 3.

Wahana AUV diberi sensor IMU sebagai sistem navigasinya yang terdiri dari akselerometer dan giroskop dengan sistem penggerak menggunakan enam baling-baling.

Pengontrol kecepatan didesain menggunakan metode Ziegler-Nichols sehingga didapatkan Kp 4900 dan Ti 1.25. Pengontrol tersebut berhasil diujikan pada wahana maupun simulasi dan menghasilkan respon yang baik. Pengontrol posisi dan sudut yaw tidak bisa didesain menggunakan metode Zigler-Nichols karena keterbatasan rentang input pwm. Dari hasil eksperimen didapatkan parameter pengontrol posisi yaitu Kp 3000, Ti 3, dan Td 0.5.

Pengujian kontrol simulasi dan respon sebenarnya memiliki kemiripan pada gerak translasi, tetapi tidak pada gerak rotasi.

\section{Daftar Pustaka}

[1] J. J. Leonard, A. A. Bennett, C. M. Smith and H. J. S. Feder, "Autonomous Underwater Vehicle Navigation," IEEE ICRA Workshop on Navigation of Outdoor Autonomous Vehicles, 1998.

[2] S. B. Williams, N. Paul, R. Julio, D. Gamini and H. Durrant-Whyte, "Autonomous underwater navigation and control.," Robotica 19.05, pp. 481496, 2001.

[3] J. Yuh, "Design and Control of Autonomous Underwater Robots: A Survey," Autonomous Robots 8.1, p. 7-24, 2000.

[4] S. O. Madgwick, "An Efficient Orientation Filter for Inertial and Inertial/Magnetic Sensor Arrays," 2010.

[5] D. H. Titterton dan J. L. Weston, Strapdown Inertial Navigation Technology -2nd Edition, Herts: The Institution of Electrical Engineers, 2004.

[6] Ogata, Katsuhiko. 2002. Modern Control Engineering, Fourth Edition. Prentice-Hall, Inc. United States of America 